\title{
Laser-Assisted 3D Printing of Carbon Fibre Reinforced Plastic Parts With Sandwiching Fibres Between Plastic Layers
}

\author{
Ken-ichiro Mori \\ Toyohashi University of Technology \\ Masahiko Yoshino \\ Tokyo Institute of Technology
}

Yuki Nakagawa ( $\square$ nakagawa.y.aw@m.titech.ac.jp )

Tokyo Institute of Technology https://orcid.org/0000-0003-4975-9002

\section{Research Article}

Keywords: 3D printing, Carbon fibre reinforced plastic, Laser heating, Tailored part

Posted Date: March 12th, 2021

DOI: https://doi.org/10.21203/rs.3.rs-277572/v1

License: (c) (i) This work is licensed under a Creative Commons Attribution 4.0 International License.

Read Full License 


\section{Abstract}

A laser-assisted 3D printing process of carbon fibre reinforced plastic parts with sandwiching fibres between plastic layers was developed to improve the bond strength of the fibres to the plastic layers. In this process, the bunded carbon fibres were placed on the 3D-printed lower layer, then the upper plastic layer was deposited on the fibres, and the two layers with sandwiching the fibres were laser-heated. The heating temperature at the interface between the fibres and the plastic layer was changed by the colour of the plastic layer because of the transmittance and absorption of laser beam, and the translucent layer was most appropriate. Not only the strength but also the rigidity of the 3D-printed carbon fibre reinforced plastic part was improved by laser heating. Carbon fibre reinforced plastic parts having closed crosssection was manufactured, and strengthened by optimisation sandwiched fibre orientation. A tailored part locally reinforced by carbon fibres was 3D-printed.

\section{Introduction}

In additive manufacturing processes, 3D parts with complex shapes are made by depositing melted resins and by laser-heated metallic and ceramics powders, layer upon layer, in precise geometric shapes using CAD or scanning data. These processes are to manufacture the 3D parts without dies and are mainly utilised for small production runs. The price of fused deposition modelling machines of plastic parts is considerably cheaper than that of selective laser meting and direct metal laser sintering machines of the metallic parts, and the application is largely expanding. In fused deposition modelling, a plastic filament is fed into a heated nozzle, then extruded through the nozzle, and deposited on a heated platform. The strength of the 3D-printed plastic parts is generally lower than that of injection moulding due to the pores included in the parts [1]. Sood et al. [2] investigated the effects of conditions of fused deposition modelling such as the layer thickness, orientation, etc. on the static strength of the parts. Dawoud et al. [3] evaluated the effect of the raster angle on the tensile, impact and bending strengths of 3D-printed parts. Turner et al. [4] reviewed the bonding behaviour of extruded plastic and its modelling in 3D printing. Although the strength of the 3D-printed parts is not very high, Nakamura et al. [5] exhibited the applicability of 3D-printed plastic dies to sheet metal forming processes such as bending and deep drawing.

To reduce the weight of automobiles, the use of CFRP (carbon fibre reinforced plastic) components increases. In resin transfer moulding for producing CFRP components, thermosetting resin is injected into a carbon fibre fabric set in a heated mould and is cured by holding for several minutes. Although the produced components have high strength, the long holding time and low resin penetration are drawbacks. These drawbacks are improved by hot stamping of composite sheets consisting of alternately laminated thermoplastic sheets and carbon fibre fabric. The composite sheets are heated, then press-formed, and solidified by cooling with dies at the bottom dead centre for several tens of seconds. Tatsuno et al. [6] investigated the effects of hot deep drawing conditions of composite sheets on the strength and quality of the formed parts. Okayasu and Sato [7] employed resistance heating for hot stamping of a composite sheet to improve the productivity, whereas the strength of the formed parts was comparatively low. Since 
the carbon fibres are not plastically deformed, it is not easy to hot-stamp parts with a complex shape due to the fibre fracture and fabric distortion.

Although fibres are manually placed to produce CFRP parts with a complex shape by autoclave moulding and resin transfer moulding, the automated fibre placement approaches have been developed [8], and the placement orientation and path for fabrication are optimised by numerical simulation. The tailored fibre placement is to optimise the mechanical properties of CRRP parts by partial control of fibre quantities and orientations [9]. Although thermosetting resin is generally employed for the automated fibre placement approaches, El-Dessouky et al. [10] applied thermoplastic resin to the reinforcement around machined holes.

CFRP parts begin to be produced by 3D printing. The CFRP parts are produced by simultaneously extruding bundled carbon fibres and plastic filament fed from different feeders through a nozzle and by moving the nozzle and platform in the planar and height directions, respectively [11]. Kabir et al. [12] reviewed recent development of 3D printing of CFRP parts. Blok et al. [13] indicated that the tensile strength of 3D-printed CFRP parts having the continuous fibres was about 9 times higher than that having short fibres. Yang et al. [14] showed that the bending and tensile strengths of CFRP parts having continuous fibres are about 2 and 5 times higher than those without the fibres, respectively. Since the strength of 3D-printed CFRP parts is generally lower than injection-moulded parts, Oztan et al. [15] observed microstructures of 3D-printed CFRP parts such as imperfect interfaces between printed layers, microvoids, incomplete filling, etc. Caminero et al. [16] evaluated the effects of the layer thickness and fibre volume content on the interlaminar bond strength of 3D-printed continuous carbon, glass and Kevlar ${ }^{\circledR}$ fibre reinforced nylon composites. Akhoundi et al. [17] indicated that the strength of 3D-printed CFRP parts with a $50 \%$ volume content of carbon fibres was almost in agreement with that calculated from the rule of mixture. Since the fibre orientation is aligned with the direction of the nozzle movement, it is not easy to control the direction requiring high strength for parts with a complex shape [18].

As another 3D printing process of CFRP parts, Mori et al. [19] sandwiched bundled carbon fibres between plastic layers without extruding fibres from a nozzle, and Nakagawa et al. [20] heated the printed part with microwave to increase the bond strength of the fibres to the plastic layers. In this process, it is easy to locally control the number and orientation of fibres, whereas microwave heating is not suitable for controlling the heating temperature. Laser heating is widely employed for welding, machining, forming, etc., and the temperature control is comparatively easy. Katayama et al. [21] developed a rapid lap joining process of metal and plastic plates without adhesives. Jaeschke et al. [22] bonded CFRP and GFRP (glass fibre reinforced plastic) sheets with laser transmission welding. Meng et al. [23] employed fibre laser for 3D printing of CFRP parts to heat an extruded composite. A laser power of several watts is sufficient to heat plastics, and the laser machines having such a power are cheap.

In this paper, laser-assisted 3D printing of CFRP parts with sandwiching fibres between plastic layers was developed to improve the strength of the parts. The bond strength of carbon fibres to the plastic layers was increased by laser heating. The effect of plastic colour in laser heating on bonding was examined. In 
addition, tailor CFRP parts with a closed cross-section were 3D-printed, and the deformation behaviour and bending strength were evaluated from the three-point bending test.

\section{Laser-assisted 3d Printing Of Cfrp Parts}

\subsection{Application of laser heating to $3 \mathrm{D}$ printing}

Laser-assisted 3D printing of CFRP parts was shown in Fig. 1. Laser heating was applied to 3D printing with sandwiching fibres between the plastic layers to increase the bond strength. First, the lower plastic layer is printed, then the bunded carbon fibres are placed on the lower layer, and the upper plastic layer is deposited on the fibres. Since the bond strength of the fibres to the plastic layers is not high for the molten upper layer, the two layers with sandwiching the fibres are heated with a blue semiconductor laser beam to heighten the bond strength. A 3D CFRP part is produced by repeating this operation. This process has the advantages of the high flexibility of number, orientation and position of carbon fibres.

Since a laser beam is transmitted and absorbed into the plastics, the heating temperature at the interface between the carbon fibre and plastic layer is changed by the colour of the plastic layer. As the colour becomes darker, the laser beam is mostly absorbed into the upper plastic layer, and thus the rise in the temperature at the interface is not high.

\subsection{Conditions of $3 \mathrm{D}$ printing}

The conditions for 3D printing are shown in Fig. 2. The polylactic acid filament having a diameter of 1.75 $\mathrm{mm}$ was extruded from the heated nozzle having a tip diameter of $0.4 \mathrm{~mm}$. The nozzle speed and temperature for printing were $50 \mathrm{~mm} / \mathrm{s}$ and $210^{\circ} \mathrm{C}$, respectively, the platform temperature was $60^{\circ} \mathrm{C}$, and the raster angle was 45 degrees. The thickness of the plastic layer was $t=0.2,0.3$ and $0.4 \mathrm{~mm}$, and the colours of the plastic were translucent, blue, grey and black. The thickness of the sandwiched bundled 1000 carbon fibres was about $0.1 \mathrm{~mm}$.

The emissivity of the plastic layer used for the temperature measurement using an infrared thermography was determined by comparing the temperature without heating between the thermography and a thermocouple, as shown in Table 1. The emissivity of translucent layer is low, and the absorption is also low.

Table 1. Emissivity of 3D printed plastics.

\begin{tabular}{|ll|}
\hline Colour & Emissivity \\
\hline Translucence & 0.30 \\
Blue & 0.80 \\
Grey & 0.50 \\
Black & 0.85 \\
\hline
\end{tabular}

Page $4 / 21$ 
The transmittance of the plastic layer for $t=0.3 \mathrm{~mm}$ was measured by an optical fibre spectrometer, as shown in Fig. 3. For laser heating having a wavelength of $445 \mathrm{~nm}$, the transmittances of the black and grey layers are considerably lower than those of the translucent and blue layers, and thus the rise in temperature is higher.

The two layers with sandwiching carbon fibres were laser-heated, as shown in Fig. 4. The laser wavelength and power were $445 \mathrm{~nm}$ and $3.6 \mathrm{~W}$, respectively, and the heating temperature decreases with increasing scanning speed. The scanning speed of the laser beam was $v=2-30 \mathrm{~mm} / \mathrm{s}$, and the heating path was indicated with the blue line. Although the focal length of the laser beam was $3 \mathrm{~mm}$, the laser was defocused by $15 \mathrm{~mm}$ to increase the heating area. The temperature of the upper surface of the upper layer was measured with the infrared thermography.

\section{Results Of Laser Heating}

\subsection{Influence of plastic colour}

The effect of defocusing on the heating temperature of the translucent plastic for $t=0.2 \mathrm{~mm}$ and $v=4.0$ $\mathrm{mm} / \mathrm{s}$ is shown in Fig. 5 . The temperature distribution on the plastic surface was measured just after the finish of laser heating. The temperature is raised by defocusing the laser beam due to the increase in irradiating area of the fibres. In the following experiment, defocusing was employed.

To examine the effect of the colour of the plastic layer on bonding of the carbon fibres, the two plastic layers with sandwiching carbon fibres were laser-heated. The effect of the scanning speed on bonding for $t=0.3 \mathrm{~mm}$ is shown in Fig. 6 . The carbon fibres were bonded to the translucent and blue plastic layers below $v=6.0$ and $4.0 \mathrm{~mm} / \mathrm{s}$, respectively. Although the carbon fibres were also bonded to the grey and black plastic layers, the holes and concavities shown in Fig. 7 appeared due to melting of the plastic layer below $v=3.0$ and $9.0 \mathrm{~mm} / \mathrm{s}$, respectively. The carbon fibres were not bonded to the plastic layers for the high scanning speed because of low temperature.

The relationship between the temperature at the plastic surface just after the finish of laser heating and the scanning speed for $t=0.3 \mathrm{~mm}$ is shown in Fig. 8. As the scanning speed increases, the temperature decreases due the reduction in amount of irradiation. For the translucent and blue plastic layers, bonding attains for a surface temperature above $100^{\circ} \mathrm{C}$ from the results shown in Fig. 6 . The trend of the temperature for the grey plastic layer is similar to that for the translucence and blue plastic layers, whereas the fibres were not bonded.

The effect of the sandwiched carbon fibres on the temperature just after the finish of laser heating for $t=$ $0.3 \mathrm{~mm}$ and $v=3.0 \mathrm{~mm} / \mathrm{s}$ is shown in Fig. 9 . Although the temperatures without the fibres for the translucent and blue layers are low due to the high transmittance, the temperature with the fibres is almost similar for the four colours. For the grey and black plastic layers, the laser beam did not reach the carbon fibres due to the large absorption of the laser beam, and thus the temperature at the interface 
between the carbon fibre and plastic layer is not high. On the other hand, for the translucent and blue layers, the laser beam reached the fibres because of high transmittance of the laser beam.

\subsection{Influence of thickness of plastic layer}

The effect of the thickness of the translucent plastic layer on laser heating is shown in Fig. 10. As the thickness decreases, the critical scanning speed for bonding increases.

The relationship between the maximum temperature of the translucent plastic surface just after the finish of heating and the scanning speed is given in Fig. 11. The temperature of the plastic surface decreases with increasing scanning speed, and the effect of the thickness of the plastic layer is small.

\section{Improvement Of Strength Of Cfrp Specimens By Laser Heating}

\subsection{Conditions for static tensile and three-point bending test}

The static tensile and bending strengths of the carbon fibre reinforced 3D printed specimens by laser heating were evaluated. The dimensions of the tensile and bending specimen and the experimental conditions are given in Fig. 12. The tensile and bending specimens are constructed by 2 and 3 plastic layers, respectively, and the thickness of the plastic layer was $t=0.3 \mathrm{~mm}$. About 9000 carbon fibres are sandwiched between the plastic layers. The specimen was laser-heated along the blue lines indicated in Fig. 12. The scanning speed was between $v=2$ and $6 \mathrm{~mm} / \mathrm{s}$.

\subsection{Results of tensile and bending test}

The load-stroke curve obtained from the tensile test for $v=2 \mathrm{~mm} / \mathrm{s}$ is shown in Fig. 13. The tensile tests were performed three times for each condition. The tensile strength of the laser-heated specimen is 2 times higher than that without fibres, whereas the increase in strength for the specimen without heating is not large.

The ruptured tensile specimen is given in Fig. 14. For no heating, the carbon fibres completely slipped from the plastic layers without cutting, and thus bonding was not attained. On the other hand, for laser heating, the fibres were fully bonded with the plastic layers, and most of the bonded fibres were cut.

The relationship between the nominal tensile strength and the scanning speed is shown in Fig. 15. The tensile strength below $v=4.0 \mathrm{~mm} / \mathrm{s}$ was high, whereas the strength above $v=5.0 \mathrm{~mm} / \mathrm{s}$ was almost similar to no heating because of not sufficient heating temperature.

The bending load-stroke curve obtained from the three-point bending test for $v=2 \mathrm{~mm} / \mathrm{s}$ is shown in Fig. 16. Not only the strength but also the rigidity is increased by laser heating.

\section{3d Printing Of Tailored Part Locally Reinforced By Carbon Fibres}




\subsection{Conditions of 3D printing}

The tailored CFRP part with a closed cross-section shown in Fig. 17 was manufactured by the developed process, and the strength of the part was evaluated. This part is a miniature of an automobile bumper beam. The bumper beams are generally produced by welding stamped parts, and it is not easy to produce parts having a complicated thickness distribution. 3D printing has the advantage of producing such complicated parts. The translucent plastic was employed, the thickness of the plastic layer is $t=0.3 \mathrm{~mm}$, and the raster angle is plus and minus $45^{\circ}$.

The part was locally reinforced by the carbon fibres, as shown in Fig. 18. The part was 3D-printed from the top with the bumper beam upside down. About 9000 fibres were sandwiched in the longitudinal and transverse directions near the projection of the part bottom with a manual operation, and one plastic layer was deposited on the fibres. After 3D printing, only the two reinforced portions were laser-heated along the blue lines indicated in Fig. 18 (d) and (e), and the scanning speed was $v=3 \mathrm{~mm} / \mathrm{s}$.

The condition for the three-point bending test of the produced part with the closed cross-section is illustrated in Fig. 19. The upper roll moved down for the fixed two lower rolls, and the speed of the upper roll was $10 \mathrm{~mm} / \mathrm{min}$.

\subsection{Results of bending test}

The bending load-stroke curves of the part with and without the fibres are shown in Fig. 20. From the first drop in load, cracks started to occur, and the parts separated at the second drop. For the set of the fibres in the longitudinal direction, the start of the cracks was earlier than that without the fibres, whereas the maximum load for that in the transverse direction was 1.2 times higher. It was found that the strength of the CFRP part is greatly influenced by the direction of the fibres.

The crack occurrence and separation for the three parts with and without the fibres are shown in Fig. 21. For no fibres, the cracks appeared around the projection of the bottom, and the occurrence of cracks was delayed by the fibres in the transverse direction, whereas the occurrence of cracks was accelerated by the fibres in the longitudinal direction. The local reinforcement in the optimum direction and position of the carbon fibres is useful for improving the strength and rigidity as tailored parts.

\section{Conclusions}

For the reduction in weight of automobiles, the use of CFRP increases, whereas it is not easy to manufacture parts having a complex shape with hot stamping of composite sheets because of the fibre fracture and fabric distortion. 3D printing processes of complex CFRP parts including tailored parts have high flexibility for the shape and reinforcement. In this study, the bond strength of the fibres to the plastic layers in 3D printing of CFRP parts was increased by laser heating, and the following results were obtained; (1) The carbon fibres were bonded to the translucent and blue plastic layers without defects, whereas holes and concavities appeared for the plastic layer the grey and black plastic layers. (2) The 
tensile strength of the translucent CFRP specimens was 2 times higher by laser heating than that without the carbon fibres. (3) A tailored part locally reinforced by carbon fibres was manufactured, and the strength was improved by optimising the fibre orientation. Since tailored parts having partial reinforcement of carbon fibres are advantageous as mechanical parts, the present 3D printing process is attractive for manufacturing the tailored parts because of the control of the amount and orientation of fibres. The combination with the finite element simulation is useful for optimising not only the shape of a part but also the amount and orientation of the fibres. Laser heating of the CFRP parts can also be applied to join other parts.

\section{Declarations}

\section{Declaration of competing interest}

The authors declare that they have no known competing financial interests or personal relationships that could have appeared to influence the work reported in this paper.

\section{Funding}

This work was supported by JSPS KAKENHI Grant-in-Aid for Early-Career Scientists of Number 20K14621 and the Grant-supported Researches in Amada Foundation of Number AF-2019230-C2.

\section{Data availability}

The data that support the findings of this study are available from the corresponding author on reasonable request.

\section{Code availability and Ethics approval}

Not applicable.

\section{References}

1. Kumar S, Kruth JP, "Composites by Rapid Prototyping Technology”, Materials \& Design, vol. 31, no. 2 pp. 850-856, 2010. http://doi.org/10.1016/j.matdes.2009.07.045

2. Sood AK, Ohdar RK, Mahapatra SS (2010) Parametric appraisal of mechanical property of fused deposition modelling processed parts. Materials Design 31:287-295. http://doi.org/10.1016/j.matdes.2009.06.016

3. Dawoud M, Taha I, Ebeid SJ (2016) Behaviour of ABS: An experimental study using FDM and injection moulding techniques. Journal of Manufacturing Processes 21:39-45.

http://dx.doi.org/10.1016/j.jmapro.2015.11.002

4. Turner BN, Strong R, Gold SA (2014) A review of melt extrusion additive manufacturing processes: I. Process design and modelling. Rapid Prototyping Journal 20(3):192-204. 
https://doi.org/10.1108/RPJ-01-2013-0012

5. Nakamura N, Mori K, Abe Y (2020) Applicability of plastic tools additively manufactured by fused deposition modelling for sheet metal forming. The International Journal of Advanced Manufacturing Technology 108:975-985. https://doi.org/10.1007/s00170-019-04590-5

6. Tatsuno D, Yoneyama T, Kawamoto K, Okamoto M, “Hot press forming of thermoplastic CFRP sheets", Procedia Manufacturing, vol. 15, pp. 1730-1737, 2018.

https://doi.org/10.1016/j.promfg.2018.07.254

7. Okayasu M, Sato M (2020) Hot-stamping technology for carbon fiber reinforced thermoplastic plates based on electrical resistance heating. J Compos Mater 54(10):1353-1361. https://doi.org/10.1177/0021998319877559

8. Zhang L, Wang X, Pei J, Zhou Y (2020) Review of automated fibre placement and its prospects for advanced composites. Journal of Materials Science 55:7121-7155.

https://doi.org/10.1007/s10853-019-04090-7

9. Mattheij P, Gliesche K, Feltin D (1998) Tailored Fiber Placement - Mechanical Properties and Applications. J Reinf Plast Compos 17(9):774-786. https://doi.org/10.1177/073168449801700901

10. DI-Dessouky HM, Saleh MN, Gautam M, Han G, Scaife RJ, Potluri P (2019) Tailored fibre placement of commingled carbon-thermoplastic fibres for notch-insensitive composites. Compos Struct 214:348-358. https://doi.org/10.1016/j.compstruct.2019.02.043

11. Matsuzaki R, Ueda M, Namiki M, Jeong TK, Asahara H, Horiguchi K, Nakamura T, Todoroki A, Hirano $Y$ (2016) Three-dimensional printing of continuous-fiber composites by in-nozzle impregnation. Sci Rep 6:23058. https://dx.doi.org/10.1038/srep23058

12. Kabir SMF, Mathur K, Seyam AFM (2020) A critical review on 3D printed continuous fibre-reinforced composites: History, mechanism, materials and properties. Compos Struct 232(15):111476. https://doi.org/10.1016/j.compstruct.2019.111476

13. Blok LG, Longana ML, Yu H, Woods BKS (2018) Investigation into 3D printing of fibre reinforced thermoplastic composites. Additive Manufacturing 22:176-186.

https://doi.org/10.1016/j.addma.2018.04.039

14. Yang C, Tian X, Liu T, Cao Y, Li D (2017) 3D printing for continuous fiber reinforced thermoplastic composites: Mechanism and performance. Rapid Prototyping Journal 23(1):209-215. https://doi.org/10.1108/RPJ-08-2015-0098

15. Oztan C, Karkkainen R, Fittipaldi M, Nygren G, Roberson L, Lane M, Celik E (2019) Microstructure and mechanical properties of three dimensional-printed continuous fiber composites. J Compos Mater 53(2):271-280. https://doi.org/10.1177/0021998318781938

16. Caminero MA, Chacón JM, Moreno IG, Reverte JM (2018) Interlaminar bonding performance of 3D printed continuous fibre reinforced thermoplastic composites using fused deposition modelling. Polym Testing 68:415-423. https://doi.org/10.1016/j.polymertesting.2018.04.038

17. Akhoundi B, Behravesh $A H$, Saed AB (2019) Improving mechanical properties of continuous fiberreinforced thermoplastic composites produced by FDM 3D printer. J Reinf Plast Compos 38(3):99- 
116. https://doi.org/10.1177/0731684418807300

18. Hou Z, Tian X, Zhang J, Li D (2018) 3D printed continuous fibre reinforced composite corrugated structure. Compos Struct 184:1005-1010. https://doi.org/10.1016/j.compstruct.2017.10.080

19. Mori K, Maeno T, Nakagawa Y (2014) Dieless forming of carbon fibre reinforced plastic parts using 3D printer. Procedia Eng 81:595-1600. https://doi.org/10.1016/j.proeng.2014.10.196

20. Nakagawa Y, Mori K, Maeno T (2017) 3D printing of carbon fibre-reinforced plastic parts. Int J Adv Manuf Technol 91:no. 5-8. https://doi.org/10.1007/s00170-016-9891-7, “"', , pp. 2811-2817

21. Katayama S, Kawahito Y, "Laser direct joining of metal and plastic", Scripta Materialia, vol. 59, pp. 1247-1250, 2008. https://doi.org/10.1016/j.scriptamat.2008.08.026

22. Jaeschke P, Wippo V, Suttmann O, Overmeyer L, "Advanced laser welding of high-performance thermoplastic composites", vol. 27, no. S2, pp. S29004, 2015. https://doi.org/10.2351/1.4906379

23. Meng L, Xiaoyong T, Junfan S, Weijun Z, Dichen L, Yingije Q (2019) Impregnation and interlayer bonding behaviours of 3D-printed continuous carbon-fiber-reinforced poly-ether-ether-ketone composites. Composites Part A 121:130-138. https://doi.org/10.1016/j.compositesa.2019.03.020

\section{Figures}

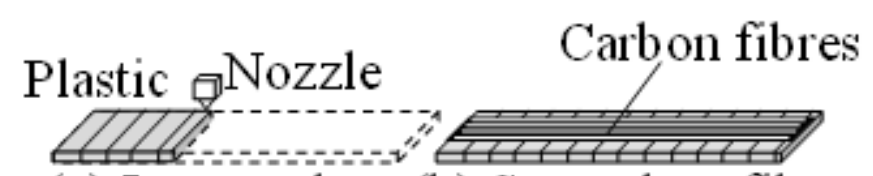

(a) Lower plate (b) Set carbon fibres (c) Upper plate

(d) End of printing (e) Laser heating
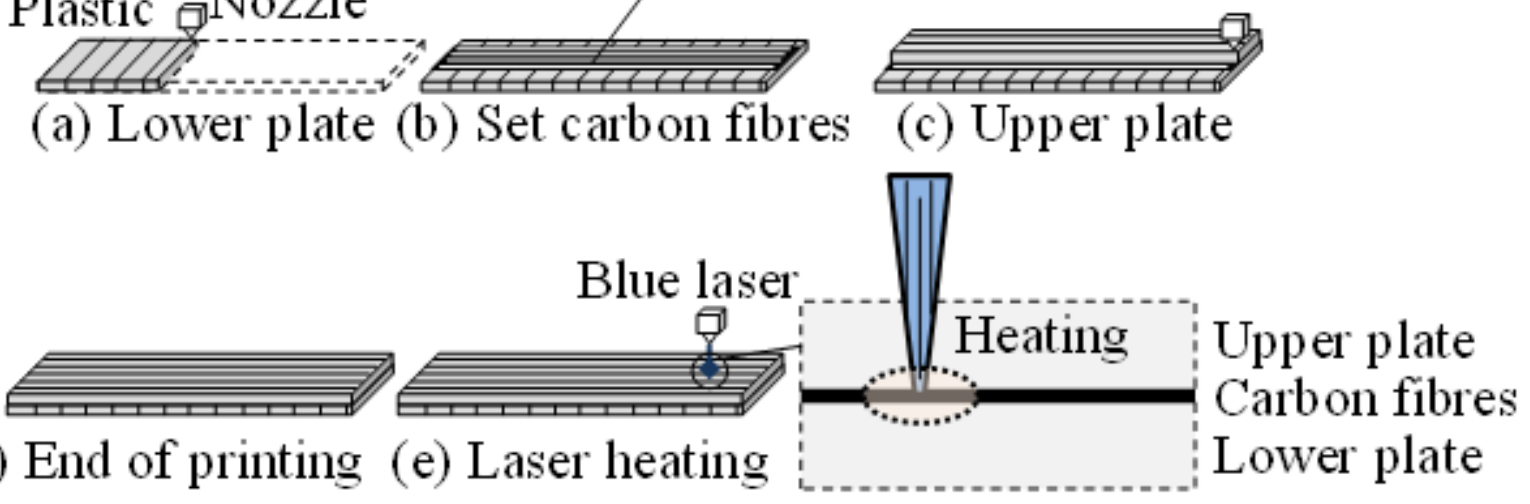

Figure 1

Laser-assisted 3D printing of CFRP parts 


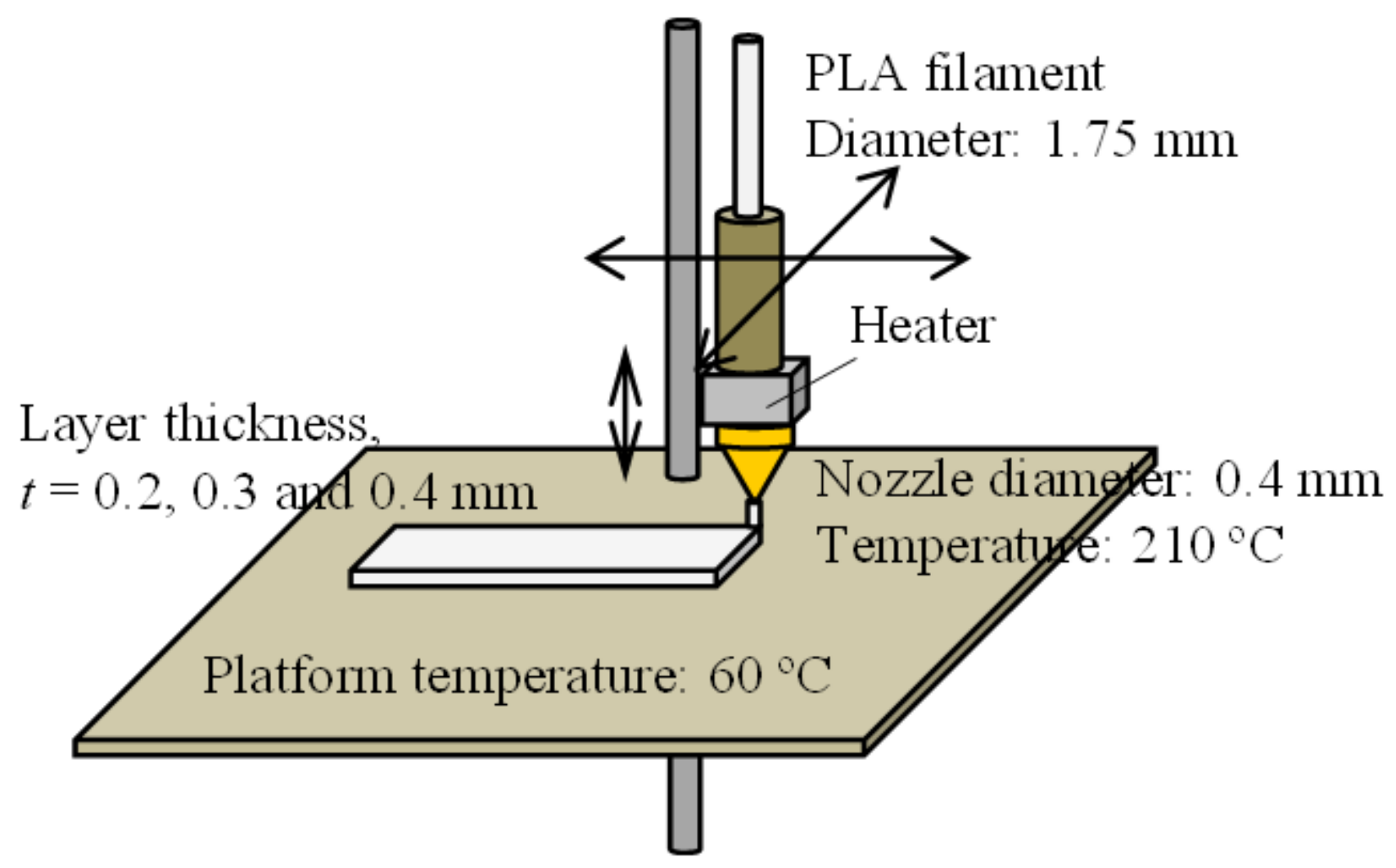

Figure 2

Conditions for 3D printing of plastic layer.

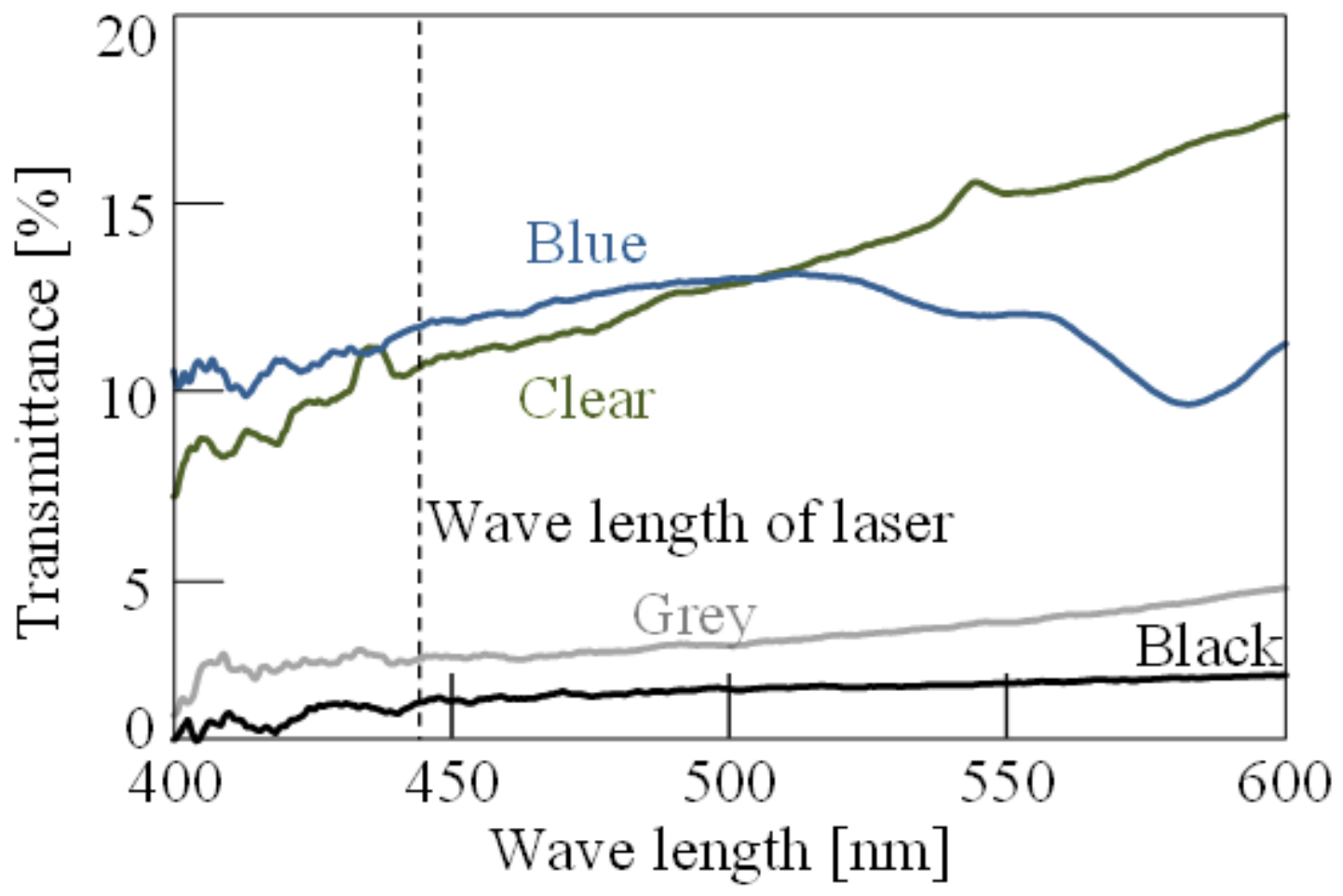

Figure 3

Transmittance of plastic layer around the laser wavelength for $t=0.3 \mathrm{~mm}$. 


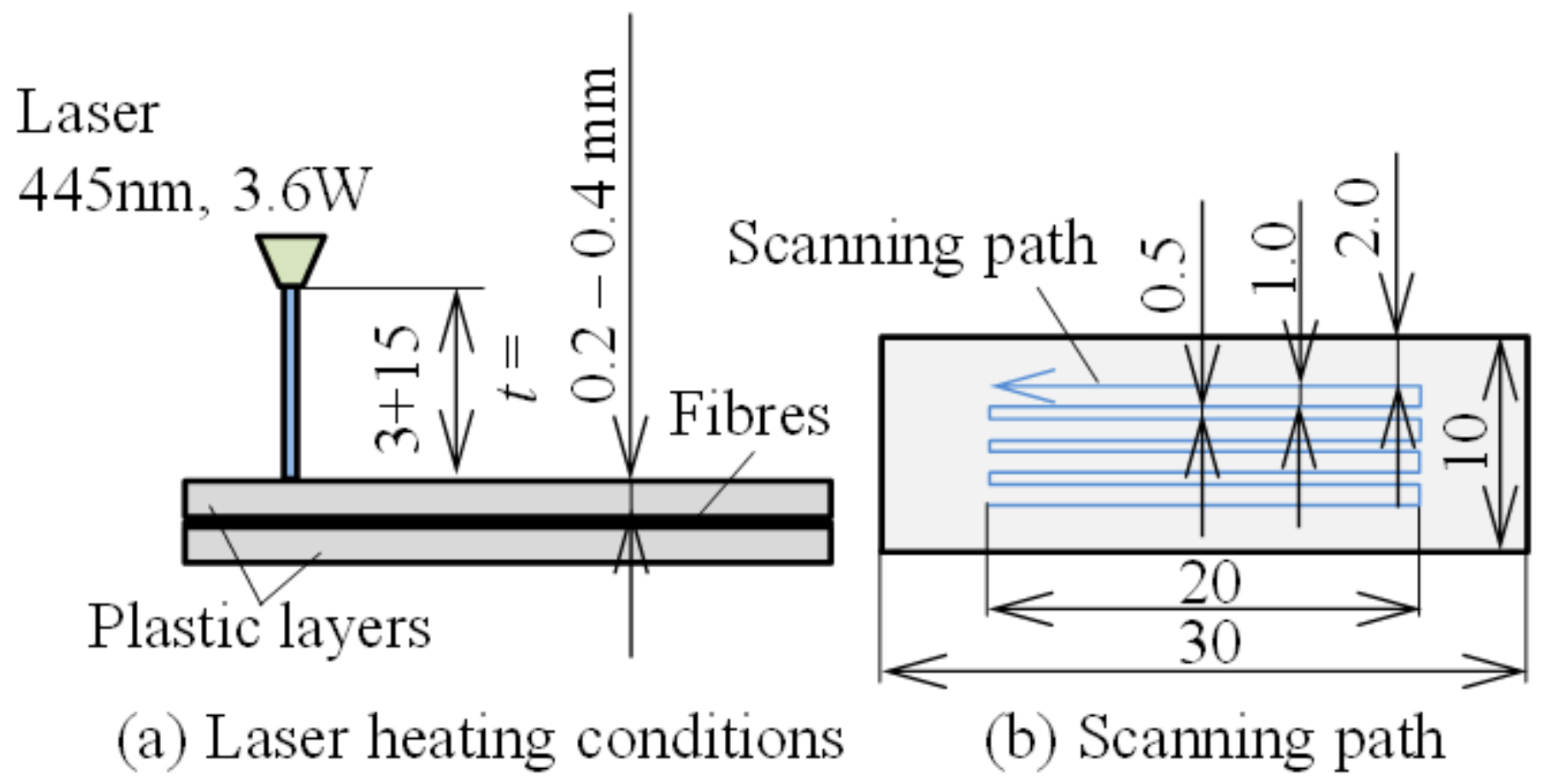

Figure 4

Laser heating conditions for plastic layers with sandwiching carbon fibres.

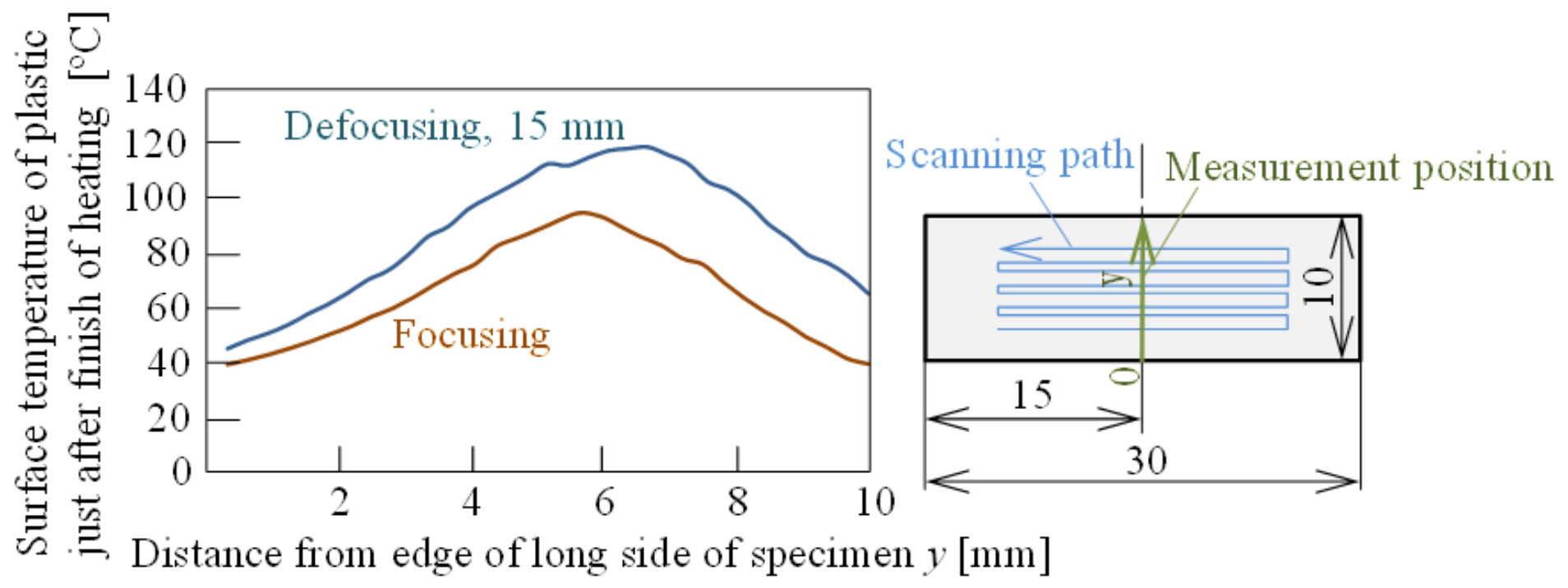

Figure 5

Effect of defocus on heating temperature of translucent plastic for $\mathrm{t}=0.2 \mathrm{~mm}$ and $\mathrm{v}=4.0 \mathrm{~mm} / \mathrm{s}$. 


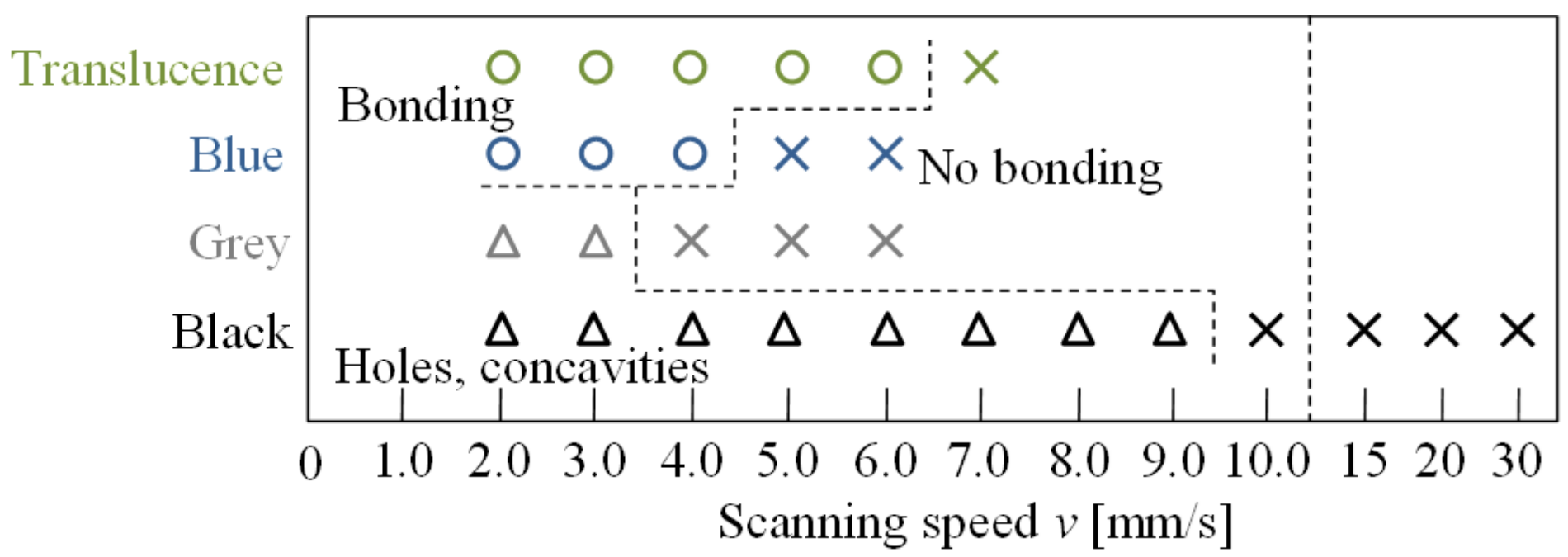

Figure 6

Effect of scanning speed on bonding for $\mathrm{t}=0.3 \mathrm{~mm}$.

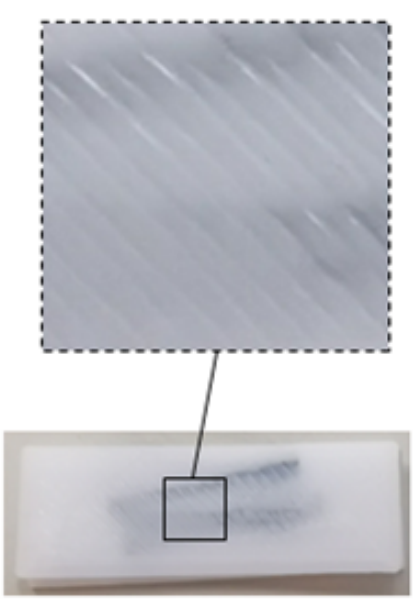

(a) Translucence

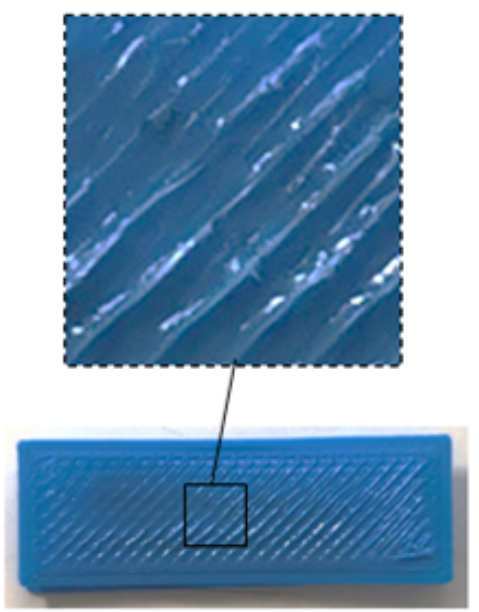

(b) Blue

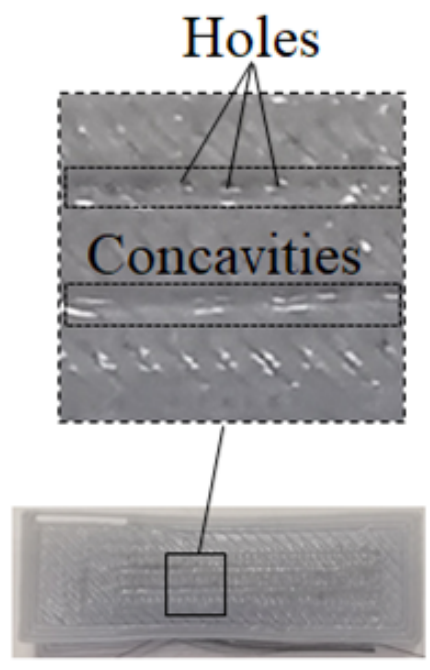

(c) Grey

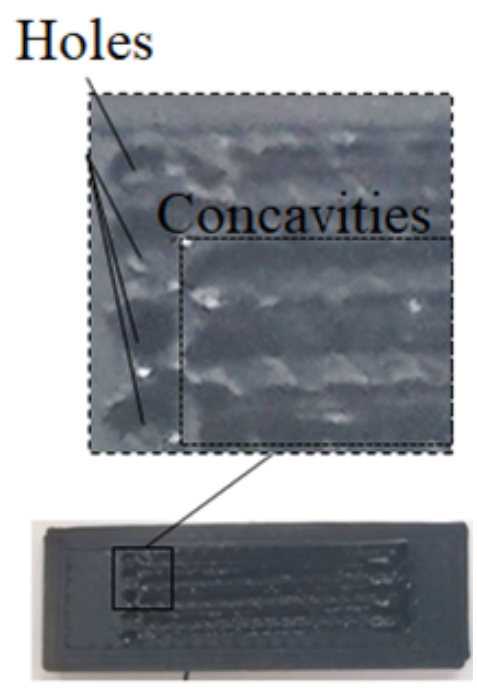

(d) Black

Figure 7

Laser heated plastic layer with sandwiching carbon fibres for $v=3.0 \mathrm{~mm} / \mathrm{s}$. 


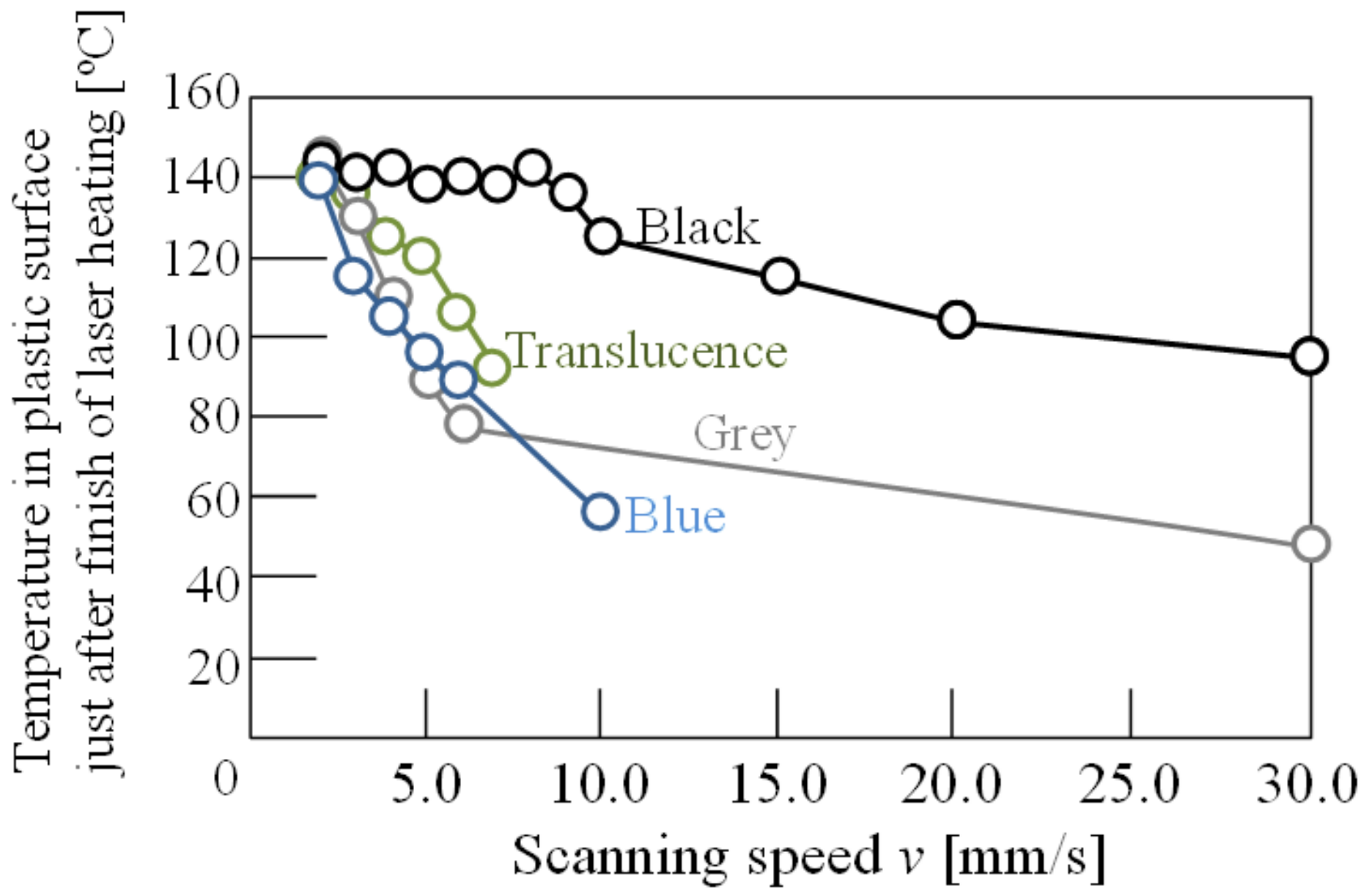

Figure 8

Relationship between temperature at plastic surface just after finish of laser heating and scanning speed for $\mathrm{t}=0.3 \mathrm{~mm}$.

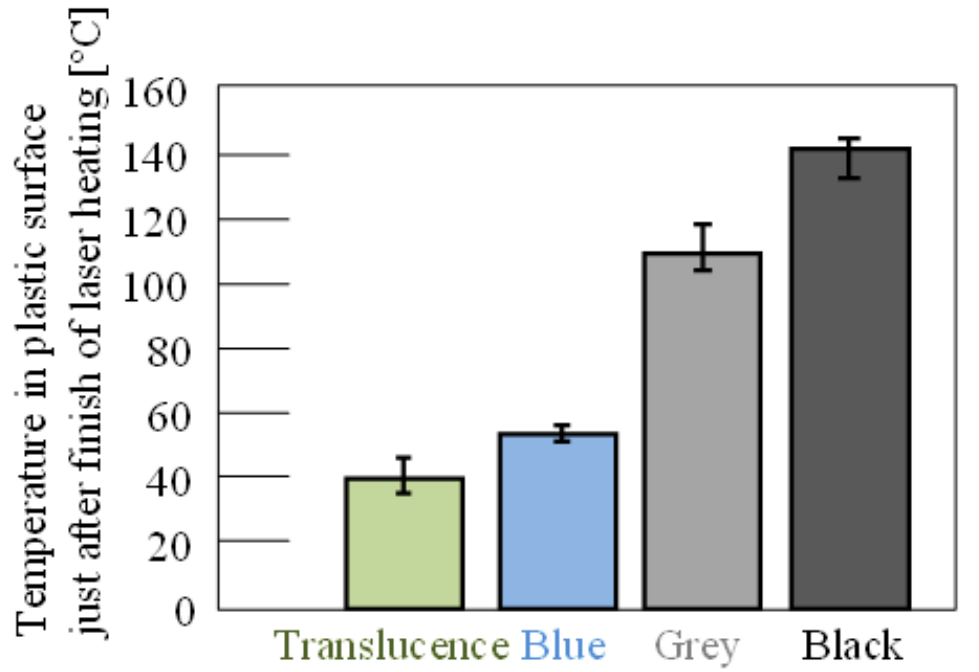

(a) Without fibres

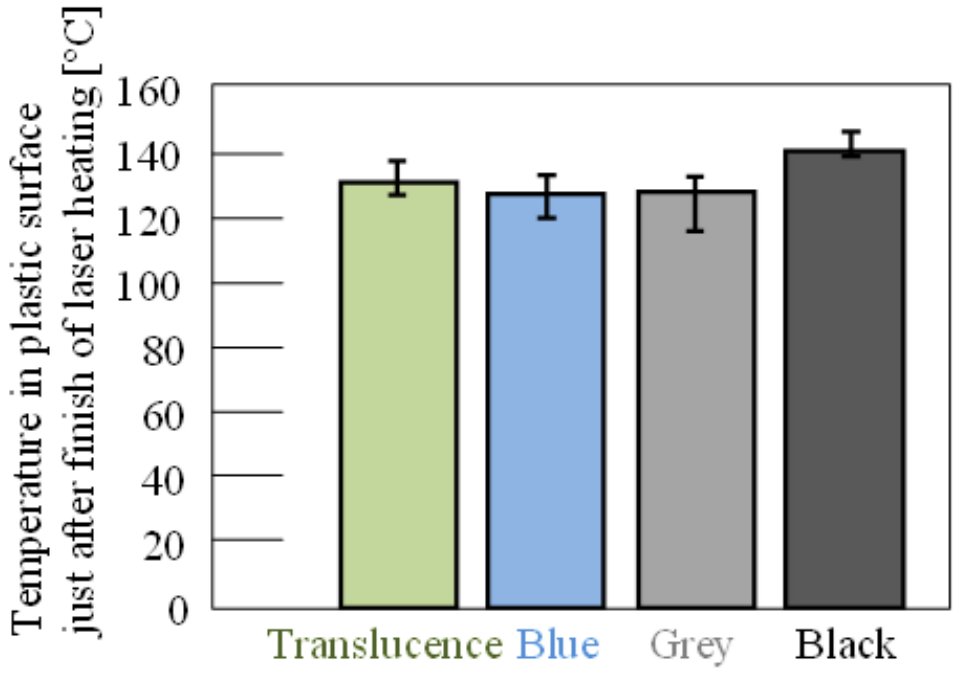

(b) With fibres

Figure 9 
Effect of sandwiched carbon fibres on temperature just after finish of laser heating for $\mathrm{t}=0.3 \mathrm{~mm}$ and $\mathrm{v}=$ $3.0 \mathrm{~mm} / \mathrm{s}$.

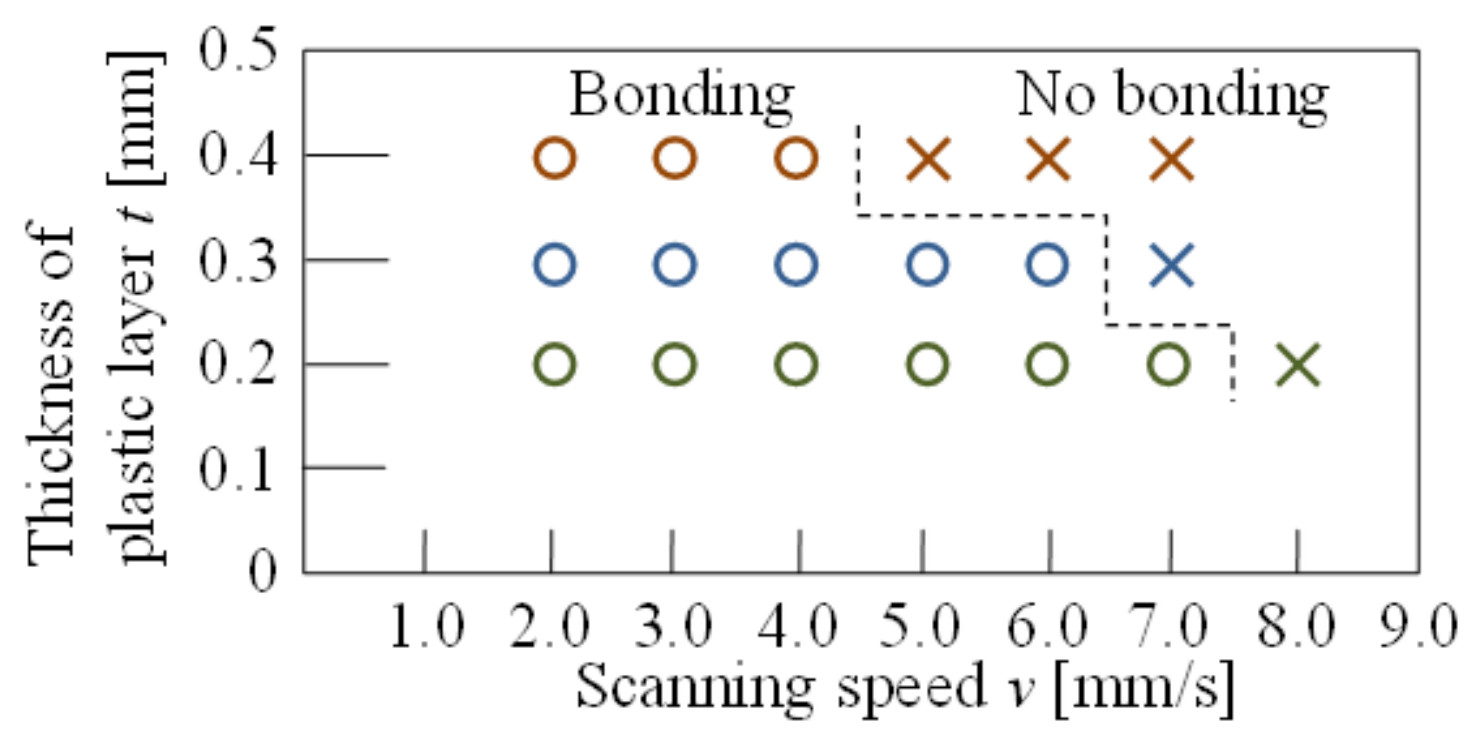

Figure 10

Effect of thickness of translucent plastic layer on laser heating.

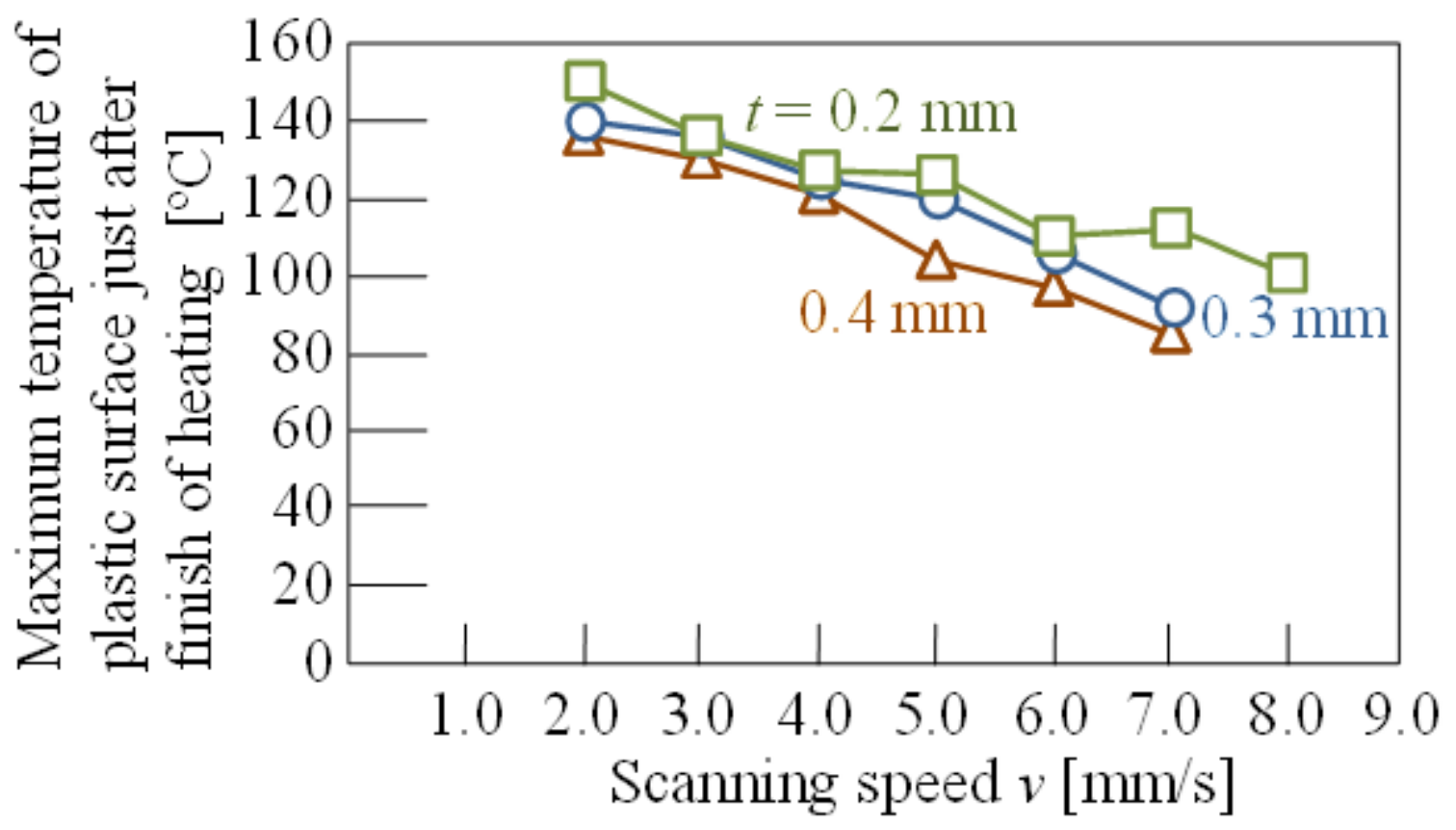

Figure 11

Relationship between maximum temperature of translucent plastic surface just after finish of heating and scanning speed. 
Tensile speed: $10 \mathrm{~mm} / \mathrm{min}$

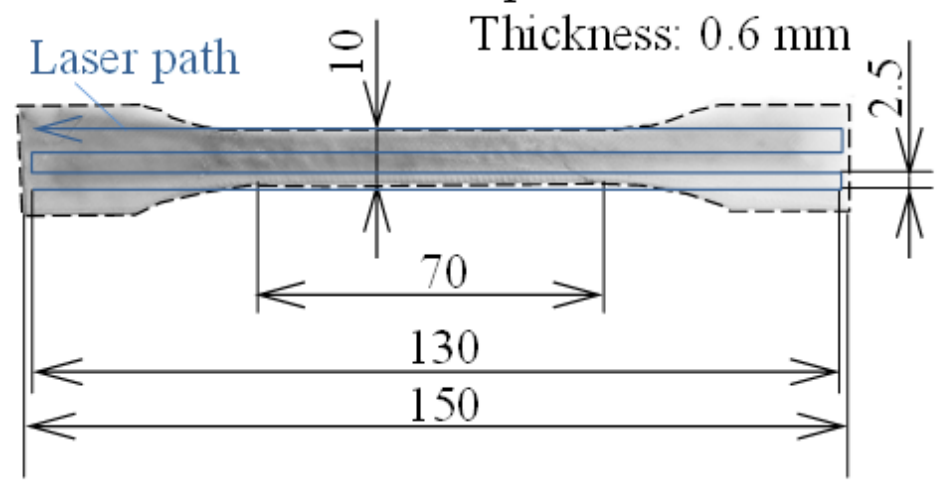

(a) Static tensile test
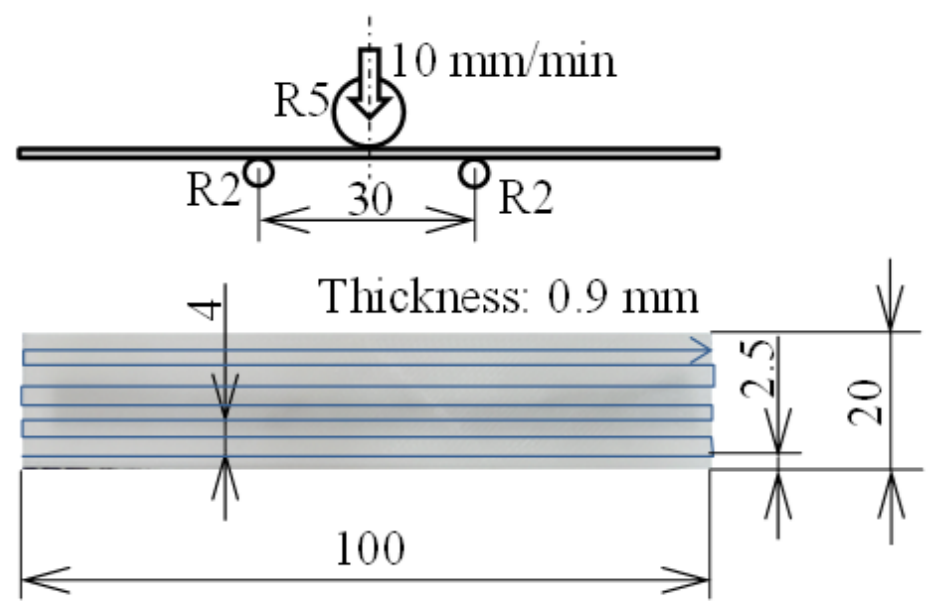

(b) Three-point bending test

\section{Figure 12}

Dimensions of tensile and bending specimen and experimental conditions.

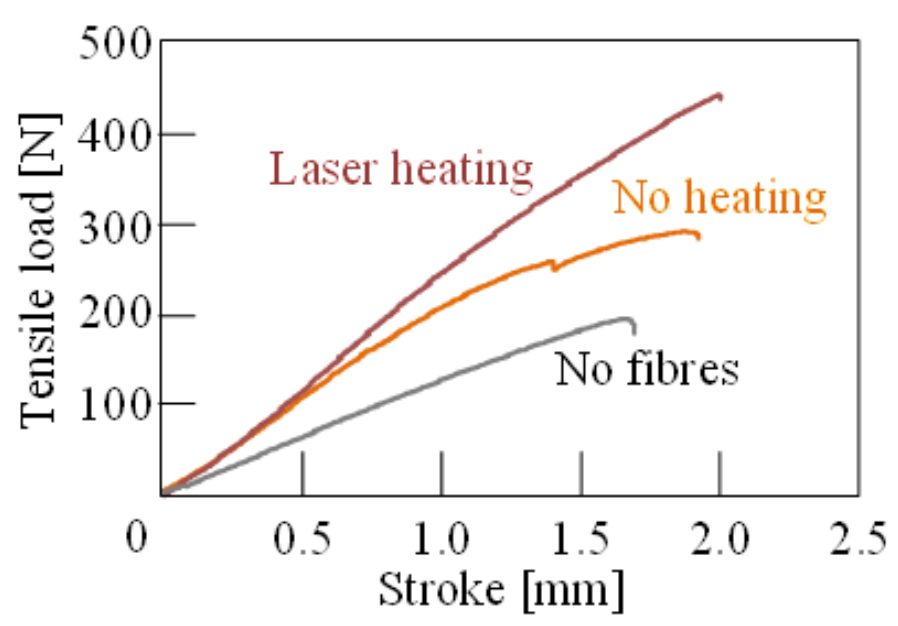

(a) Load-stroke curve

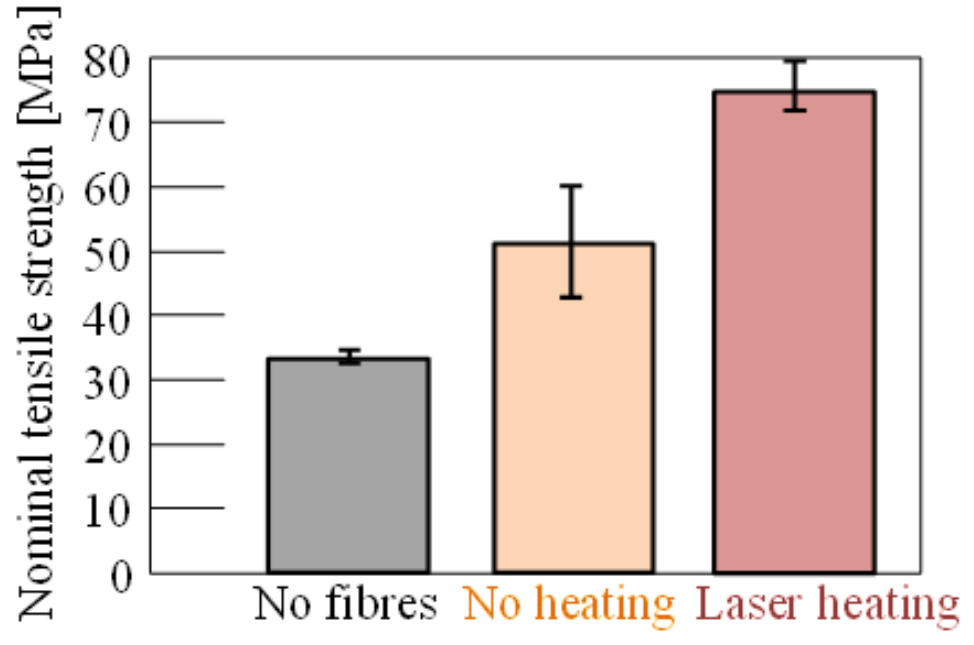

(b) Nominal tensile strength

\section{Figure 13}

(a) Load-stroke curve and (b) nominal tensile strength obtained from tensile test for $\mathrm{v}=2 \mathrm{~mm} / \mathrm{s}$. 


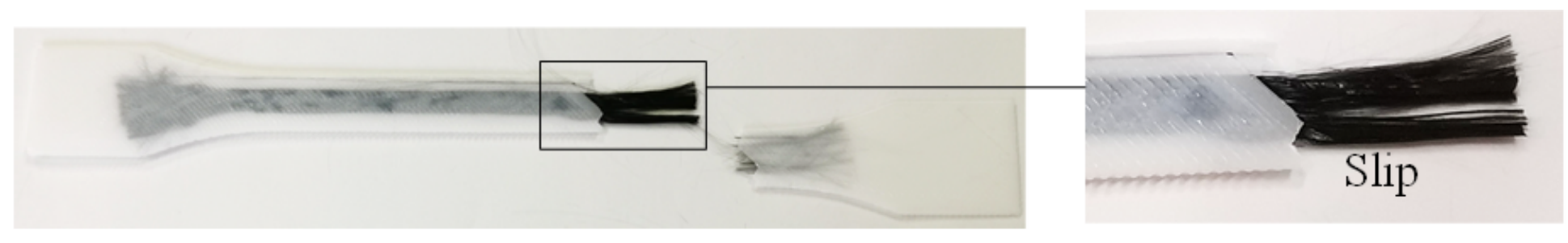

\section{(a) No heating}

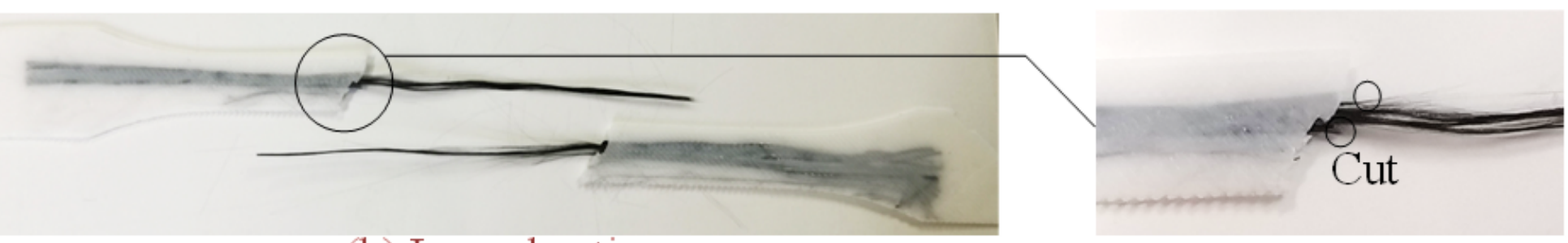

(b) Laser heating

Figure 14

Ruptured tensile specimen (a) without and (b) with laser heating for $\mathrm{v}=2 \mathrm{~mm} / \mathrm{s}$.

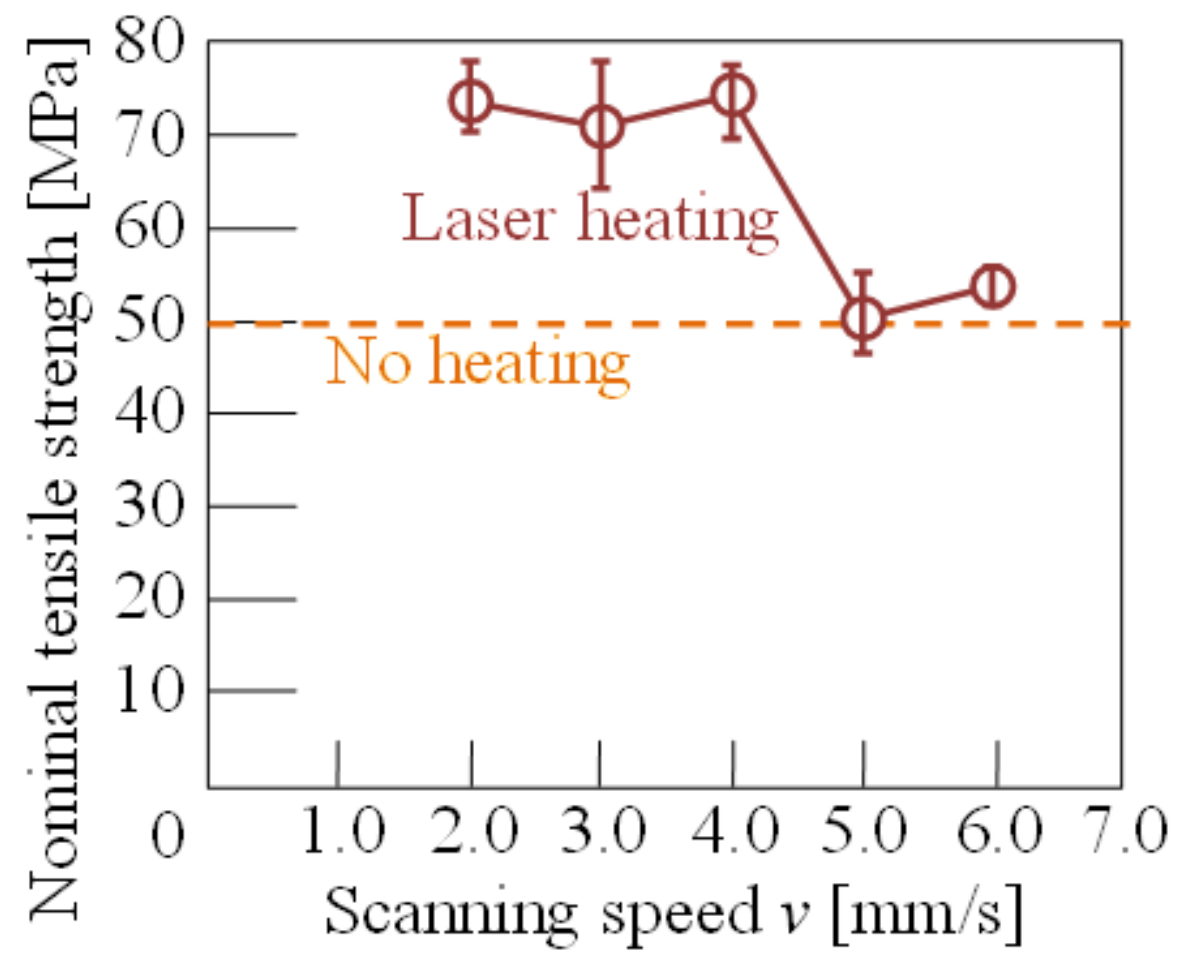

Figure 15

Relationship between nominal tensile strength and scanning speed. 


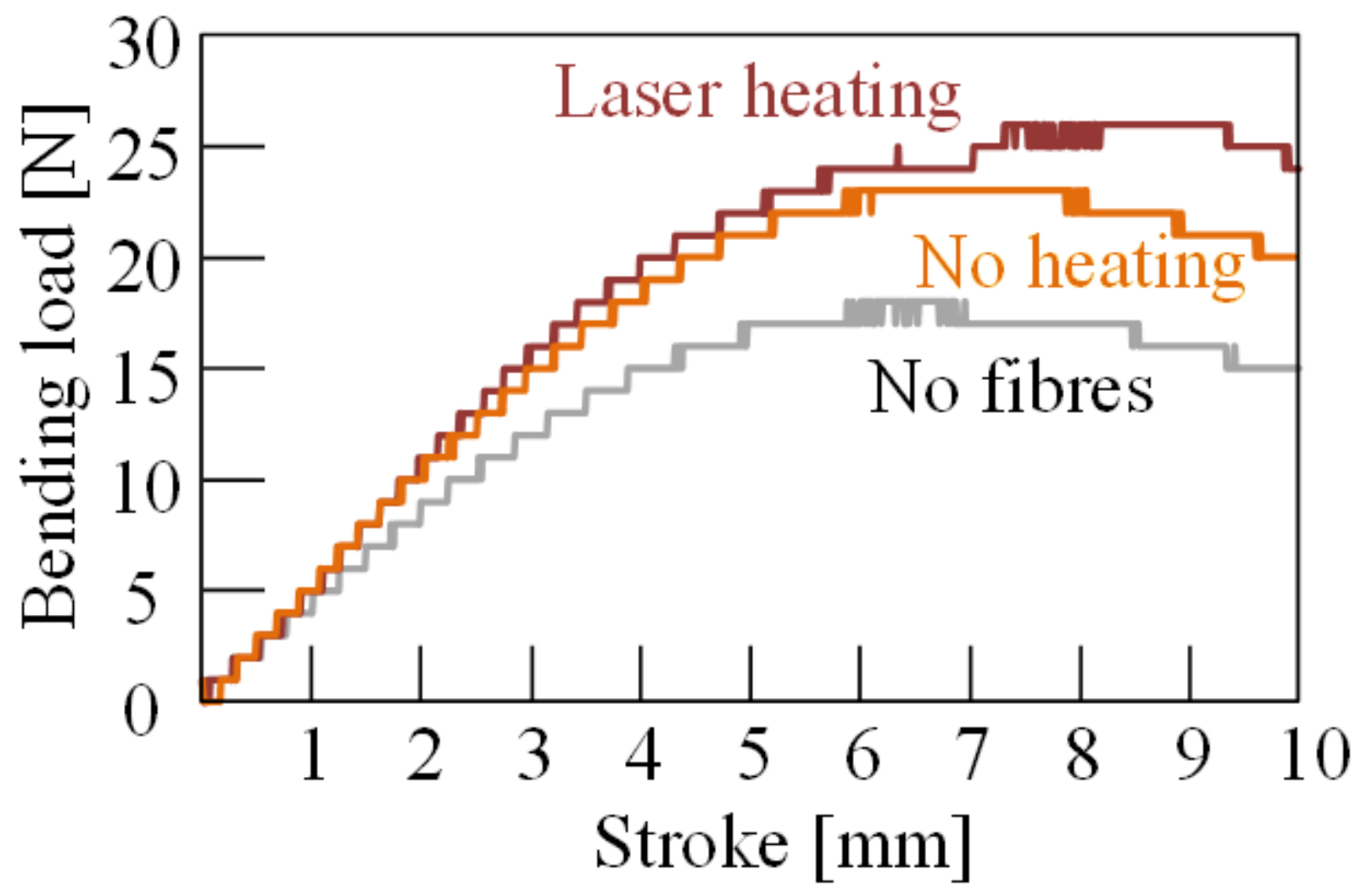

Figure 16

Bending load-stroke curve obtained from three-point bending test for $\mathrm{v}=2 \mathrm{~mm} / \mathrm{s}$.

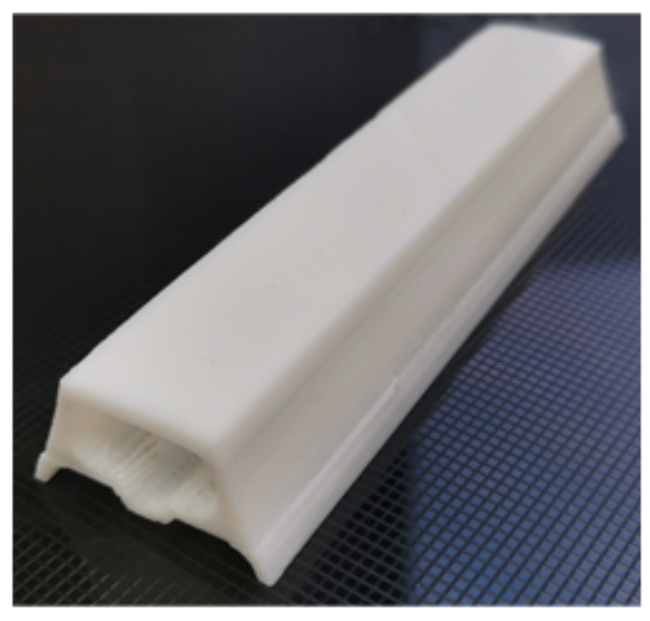

(a) Tailored CFRP part with closed cross-section

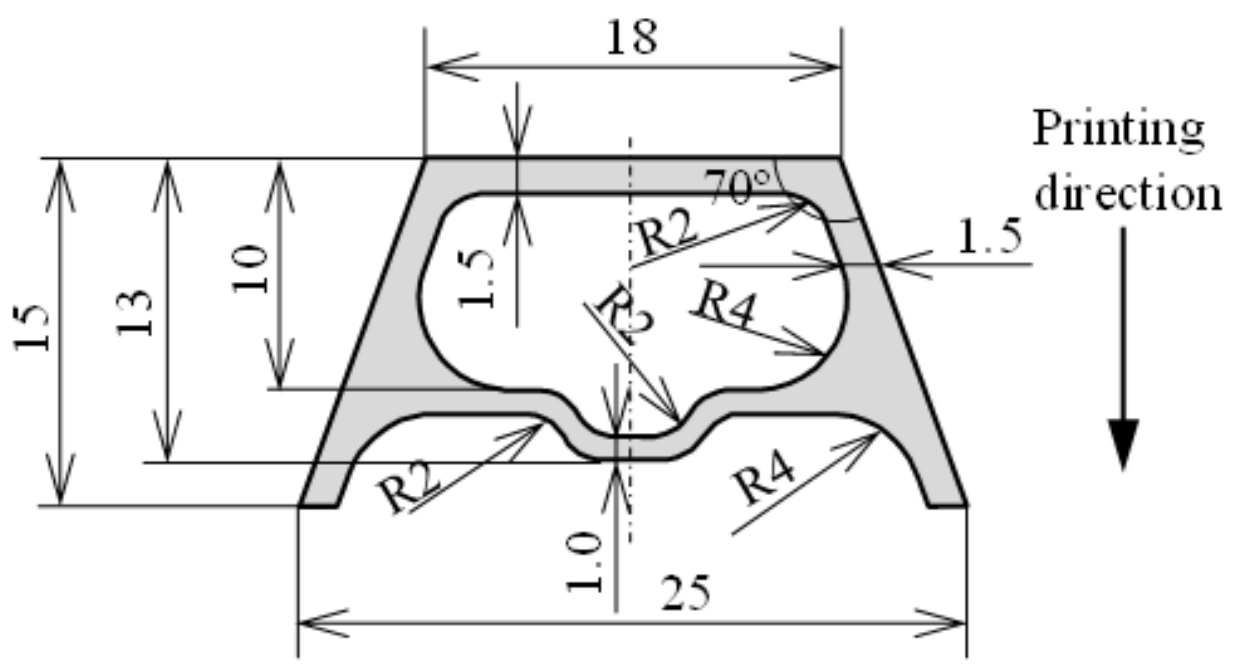

(b) Cross-section of part

Figure 17

Dimensions of tailored CFRP part with closed cross-section. 


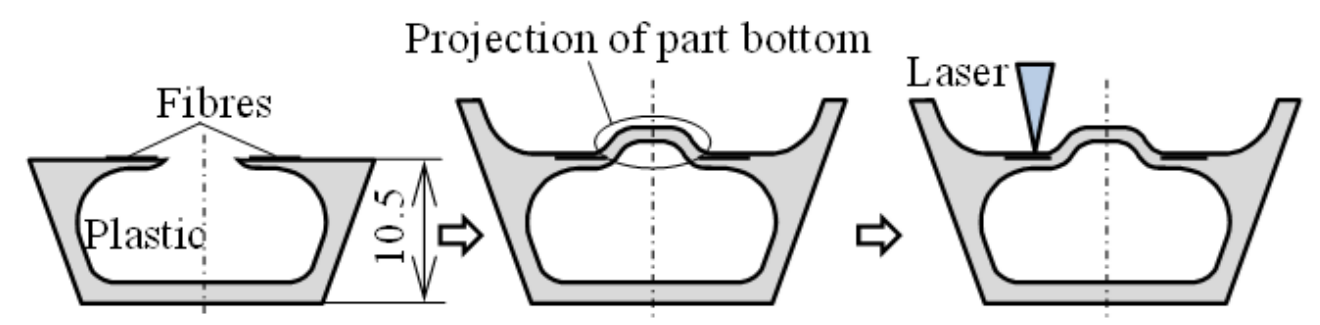

(a) Set carbon fibres

(b) Finish of 3D printing

(c) Laser heating

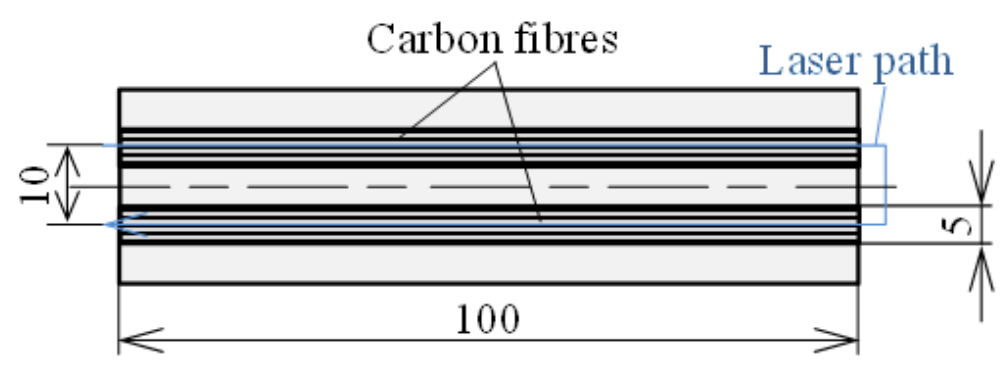

(d) Longitudinal

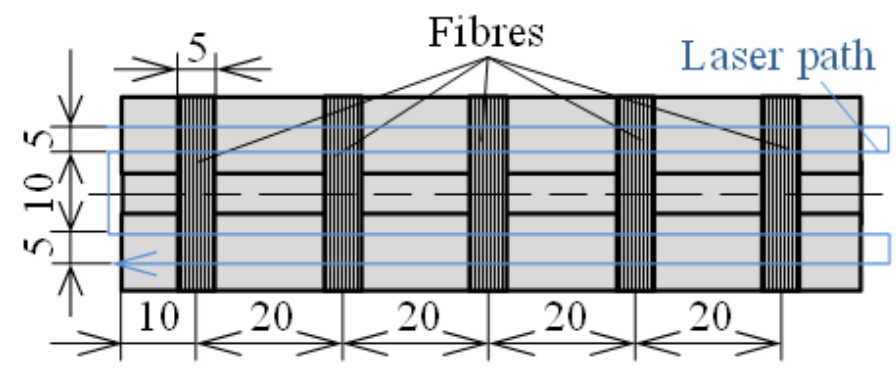

(e) Transverse

\section{Figure 18}

Procedures for sandwiching carbon fibres and laser heating.
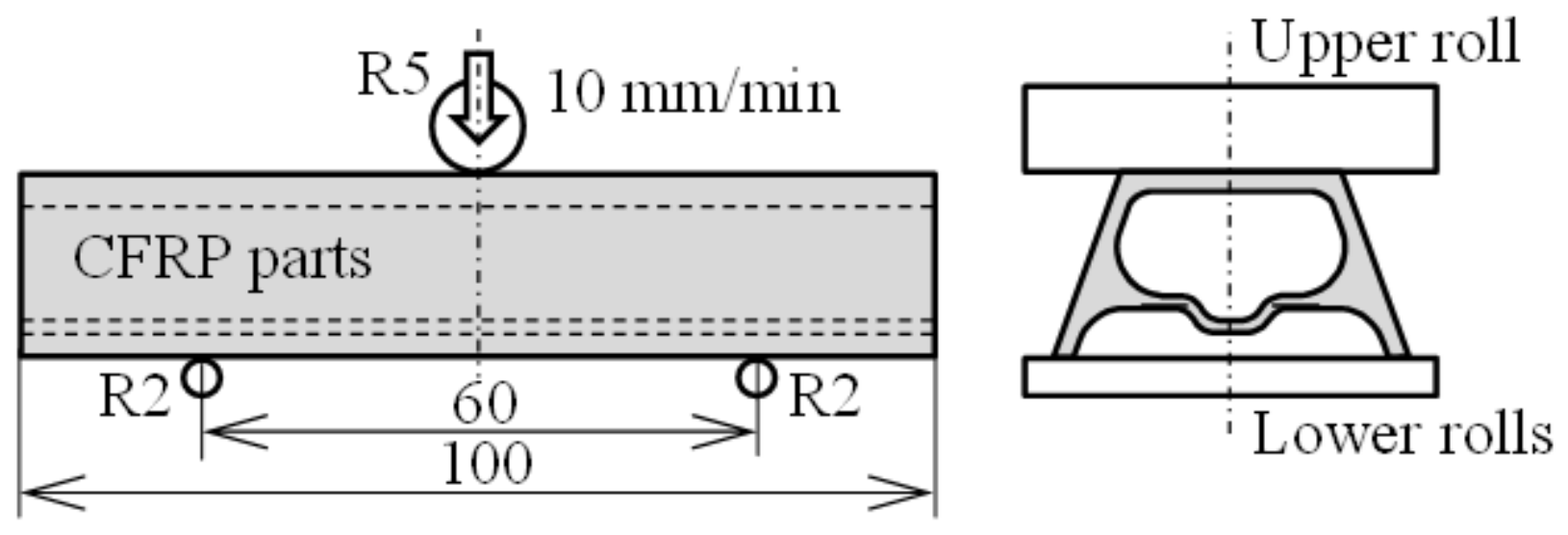

Figure 19

Conditions for three-point bending test of part with closed cross-section 


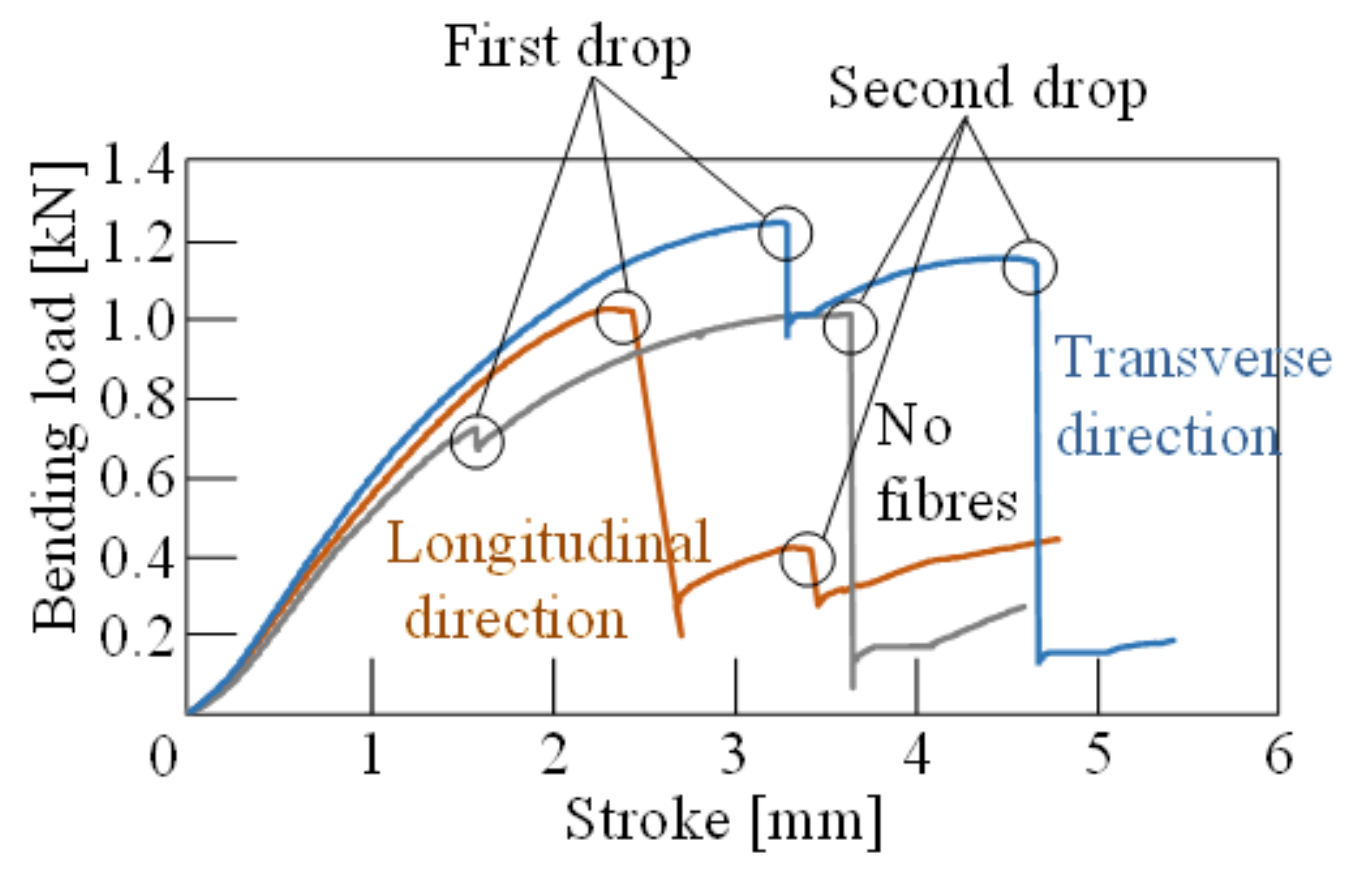

Figure 20

Bending load-stroke curves of CFRP part with and without fibres. 

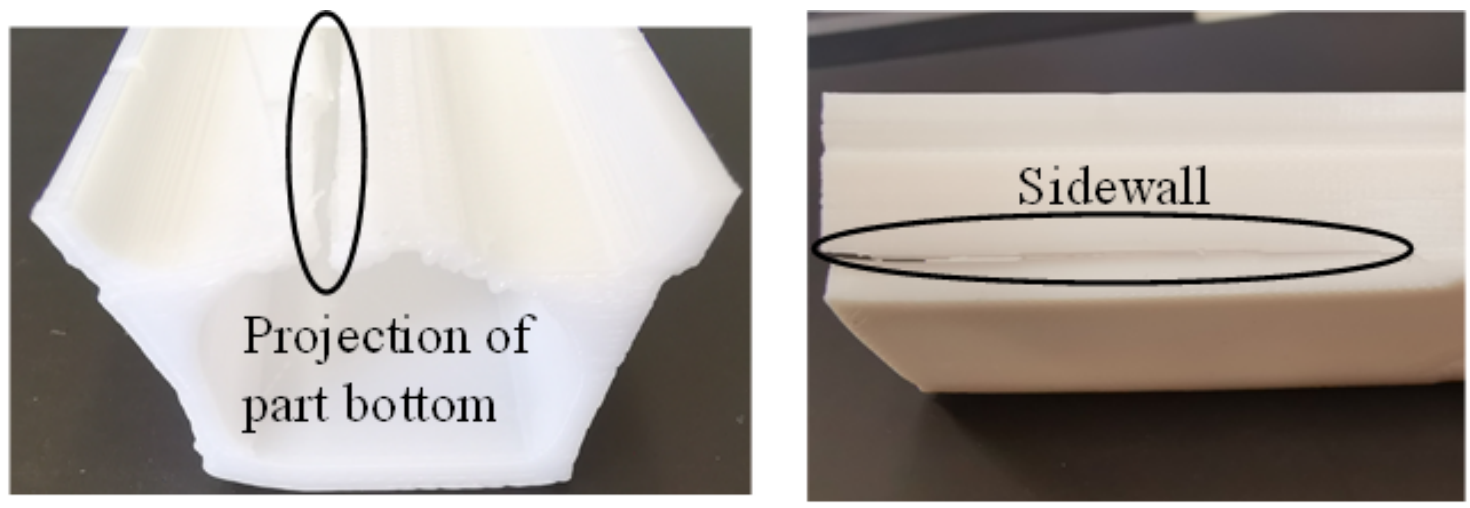

(a) No fibres
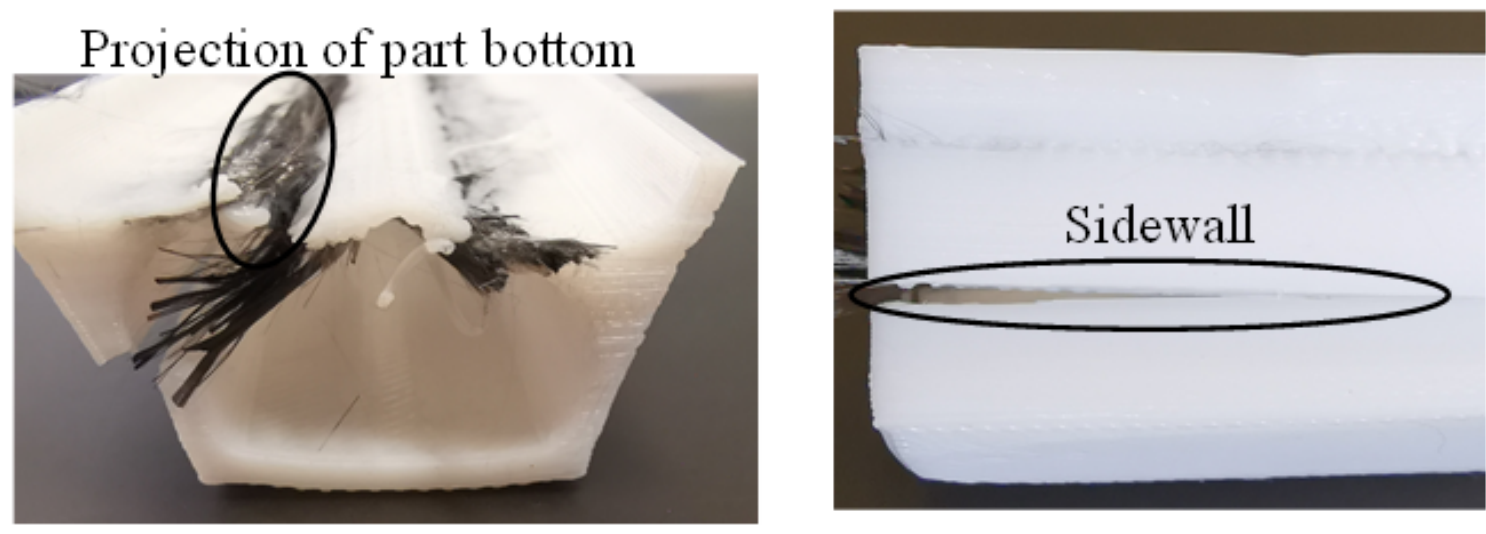

(b) Longitudinal direction
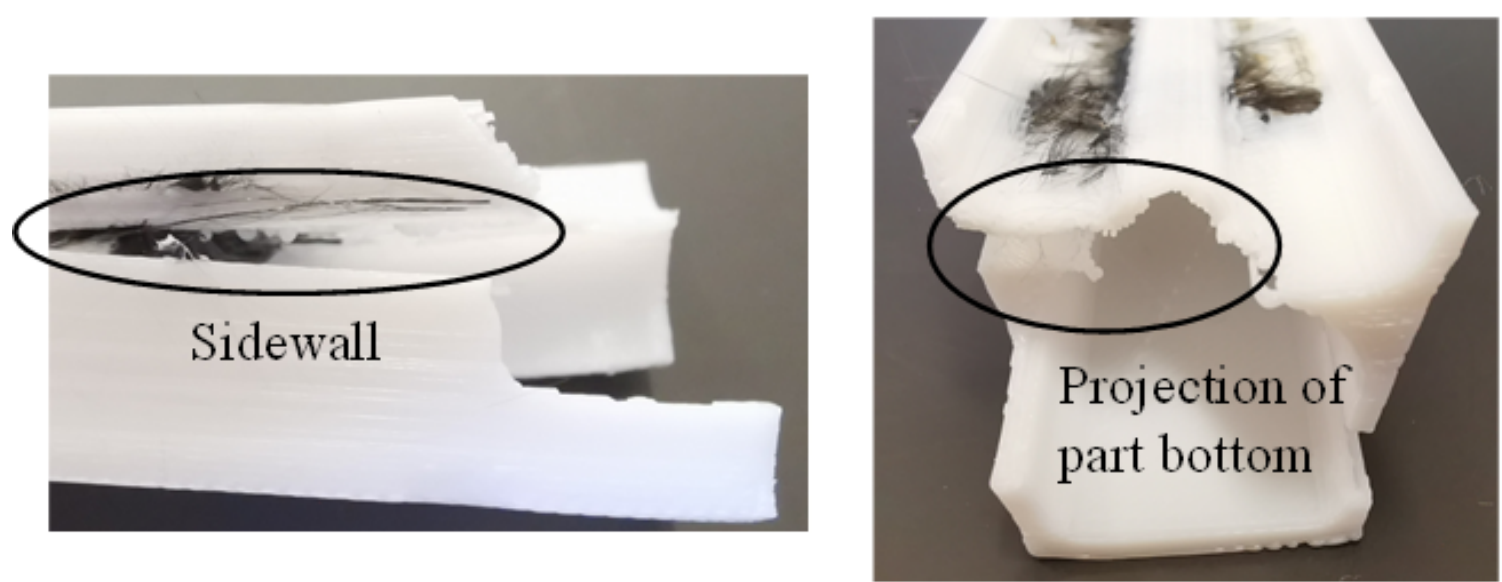

(c) Transverse direction
(i) First drop
(ii) Second drop

Figure 21

Crack occurrence and separation for three parts with and without fibres. 